\title{
Design a Novel SISO Off-line Tuning of Modified PID Fuzzy Sliding Mode Controller
}

\author{
Ali Shahcheraghi, Farzin Piltan, Masoud Mokhtar, Omid Avatefipour, Alireza Khalilian \\ Institute of Advance Science and Technology, Intelligent control and Robotics Lab. IRAN SSP, Shiraz, Iran \\ E-mail: Piltan_f@iranssp.com; http://WWW.IRANSSP.COM
}

\begin{abstract}
The Proportional Integral Derivative (PID) Fuzzy Sliding Mode Controller (FSMC) is the most widely used control strategy in the Industry (control of robotic arm). The popularity of PID FSMC controllers can be attributed to their robust performance in a wide range of operating conditions and partly to their functional simplicity. The process of setting of PID FSMC controller can be determined as an optimization task. Over the years, use of intelligent strategies for tuning of these controllers has been growing. Biologically inspired evolutionary strategies have gained importance over other strategies because of their consistent performance over wide range of process models and their flexibility. This paper analyses the modified PID FSMC controllers based on minimum rule base for flexible robot manipulator system and test the quality of process control in the simulation environment of MATLAB/SIMULINK Simulator.
\end{abstract}

Index Terms - PID Control, Sliding Mode Control, Fuzzy Logic Methodology, Robust Controller, Flexible Robot Manipulator

\section{Introduction}

Gradient Descent Optimization (GDO) is one of the evolutionary optimization algorithms in the branch of non intelligence [1]. This algorithm was inspired by the social movement behavior of the birds in the flock searching for food. Compared to the other evolutionary algorithms, the main excellences of this algorithm are: Simple concept, easy to implement, robustness in tuning parameters, minimum storage space and both global and local exploration capabilities. These birds in a flock are symbolically described as particles. These particles are supposed to a swarm "flying" through the problem space. Each particle has a position and a velocity. Any particle's position in the problem space has one solution for the problem. When a particle transfers from one place to another, a different problem solution is generated. Cost function evaluated the solution in order to provide the fitness value of a particle. "Best location" of each particle which has experienced up to now, is recorded in their memory, in order to determine the best fitness value. Continuum robots represent a class of robots that have a biologically inspired form characterized by flexible backbones and high degreesof-freedom structures [1]. The idea of creating "trunk and tentacle" robots, (in recent years termed continuum robots [1]), is not new [2]. Inspired by the bodies of animals such as snakes [3], the arms of octopi [4], and the trunks of elephants [5-6], researchers have been building prototypes for many years. A key motivation in this research has been to reproduce in robots some of the special qualities of the biological counterparts. This includes the ability to "slither" into tight and congested spaces, and (of particular interest in this work) the ability to grasp and manipulate a wide range of objects, via the use of "whole arm manipulation" i.e. wrapping their bodies around objects, conforming to their shape profiles. Hence, these robots have potential applications in whole arm grasping and manipulation in unstructured environments such as rescue operations. Theoretically, the compliant nature of a continuum robot provides infinite degrees of freedom to these devices. However, there is a limitation set by the practical inability to incorporate infinite actuators in the device. Most of these robots are consequently under actuated (in terms of numbers of independent actuators) with respect to their anticipated tasks. In other words they must achieve a wide range of configurations with relatively few control inputs. This is partly due to the desire to keep the body structures (which, unlike in conventional rigidlink manipulators or fingers, are required to directly contact the environment) "clean and soft", but also to exploit the extra control authority available due to the continuum contact conditions with a minimum number of actuators. For example, the Octarm VI continuum manipulator, discussed frequently in this paper, has nine independent actuated degrees-of-freedom with only three sections. Continuum manipulators differ fundamentally from rigid-link and hyper-redundant robots by having an unconventional structure that lacks links and joints. Hence, standard techniques like the Denavit-Hartenberg (D-H) algorithm cannot be directly applied for developing continuum arm kinematics. Moreover, the design of each continuum arm varies with respect to the flexible backbone present in the system, the positioning, type and number of actuators. The constraints imposed by these factors make the set of reachable configurations and nature of movements unique to every continuum robot. This makes it difficult to formulate generalized kinematic or dynamic models for continuum robot hardware. Chirikjian and Burdick 
were the first to introduce a method for modeling the kinematics of a continuum structure by representing the curve-shaping function using modal functions [5-6]. Mochiyama used the Serret- Frenet formulae to develop kinematics of hyper-degrees of freedom continuum manipulators [5].

Controller is a device which can sense information from linear or nonlinear system (e.g., flexible robot) to improve the systems performance [7-20]. The main targets in design control systems are stability, good disturbance rejection, and small tracking error[7, 21-30] Several robot are controlled by linear methodologies (e.g., Proportional-Derivative (PD) controller, Proportional- Integral (PI) controller or ProportionalIntegral-Derivative (PID) controller), but when robot works with various payloads and have uncertainty in dynamic models this technique has limitations. In some applications continuum robot are used in an unknown and unstructured environment, therefore strong mathematical tools used in new control methodologies to design nonlinear robust controller with an acceptable performance (e.g., minimum error, good trajectory, disturbance rejection) [31-45].

Sliding mode controller is an influential nonlinear controller to certain and uncertain systems which it is based on system's dynamic model. Sliding mode controller is a powerful nonlinear robust controller under condition of partly uncertain dynamic parameters of system [40-55]. This controller is used to control of highly nonlinear systems especially for continuum robot. Chattering phenomenon and nonlinear equivalent dynamic formulation in uncertain dynamic parameter are two main drawbacks in pure sliding mode controller [20, 46-55]. The chattering phenomenon problem in pure sliding mode controller is reduced by using linear saturation boundary layer function but prove the stability is very difficult.

Gradient descent is a first-order optimization algorithm. Gradient descent works in spaces of any number of dimensions, even in infinite-dimensional ones. In the latter case the search space is typically a function space, and one calculates the Gâteaux derivative of the functional to be minimized to determine the descent direction. The gradient descent can take much iteration to compute a local minimum with a required accuracy, if the curvature in different directions is very different for the given function. This method is based on resolve the sliding surface slope and fuzzy logic gain updating factor as well as improve the output performance by Gradient Descent Optimal Algorithm (GDOA) tuning the sliding surface slope and gain updating factor coefficients. The sliding surface gain $(\boldsymbol{\lambda})$ and gain updating factor of this controller is adjusted off line depending on the iterations.

Although the fuzzy-logic control is not a new technique, its application in this current research is considered to be novel since it aimed for an automated dynamic-less response rather than for the traditional objective of uncertainties compensation[38]. The intelligent tracking control using the fuzzy-logic technique provides a cost-and-time efficient control implementation due to the automated dynamic-less input. This in turn would further inspire multiuncertainties testing for continuum robot [38].

This paper is organized as follows; section 2, is served as an introduction to the sliding mode controller formulation algorithm and its application to control of continuum robot, dynamic of continuum robot and proof of stability and fuzzy inference system. Part 3, introduces and describes the methodology (gradient descent tuning fuzzy sliding mode controller) algorithm. Section 4 presents the simulation results and discussion of this algorithm applied to a continuum robot and the final section describe the conclusion.

\section{Theory}

\subsection{Dynamic Formulation of Continuum Robot}

The Continuum section analytical model developed here consists of three modules stacked together in series. In general, the model will be a more precise replication of the behavior of a continuum arm with a greater of modules included in series. However, we will show that three modules effectively represent the dynamic behavior of the hardware, so more complex models are not motivated. Thus, the constant curvature bend exhibited by the section is incorporated inherently within the model. The model resulting from the application of Lagrange's equations of motion obtained for this system can be represented in the form

$$
F_{\text {coeff }} \underline{\tau}=D(\underline{q}) \underline{\ddot{q}}+C(\underline{q}) \underline{\dot{q}}+G(\underline{q})
$$

where $\tau$ is a vector of input forces and $\mathrm{q}$ is a vector of generalized co-ordinates. The force coefficient matrix $F_{\text {coeff }}$ transforms the input forces to the generalized forces and torques in the system. The inertia matrix, $D$ is composed of four block matrices. The block matrices that correspond to pure linear accelerations and pure angular accelerations in the system (on the top left and on the bottom right) are symmetric. The matrix $C$ contains coefficients of the first order derivatives of the generalized co-ordinates. Since the system is nonlinear, many elements of $C$ contain first order derivatives of the generalized co-ordinates. The remaining terms in the dynamic equations resulting from gravitational potential energies and spring energies are collected in the matrix $G$. The coefficient matrices of the dynamic equations are given below,

$$
\begin{aligned}
& \text { FCOeff }= \\
& {\left[\begin{array}{cccccc}
1 & 1 & \cos \left(\theta_{1}\right) & \cos \left(\theta_{1}\right) & \cos \left(\theta_{1}+\theta_{2}\right) & \cos \left(\theta_{1}+\theta_{2}\right) \\
0 & 0 & 1 & 1 & \cos \left(\theta_{2}\right) & \cos \left(\theta_{2}\right) \\
0 & 0 & 0 & 0 & 1 & 1 \\
1 / 2 & -1 / 2 & 1 / 2 & -1 / 2 & 1 / 2+s_{2} \sin \left(\theta_{2}\right) & -1 / 2+s_{2} \sin \left(\theta_{2}\right) \\
0 & 0 & 1 / 2 & -1 / 2 & 1 / 2 & -1 / 2 \\
0 & 0 & 0 & 0 & 1 / 2 & -1 / 2
\end{array}\right]}
\end{aligned}
$$




$$
\begin{aligned}
& D(\underline{q})=
\end{aligned}
$$

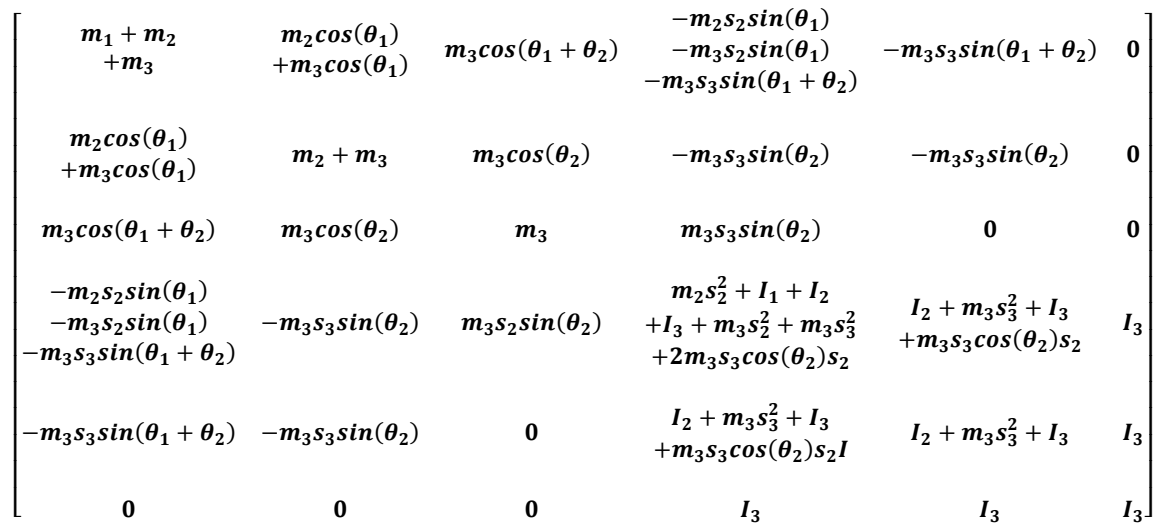

$$
\begin{aligned}
& c(\underline{q})=
\end{aligned}
$$

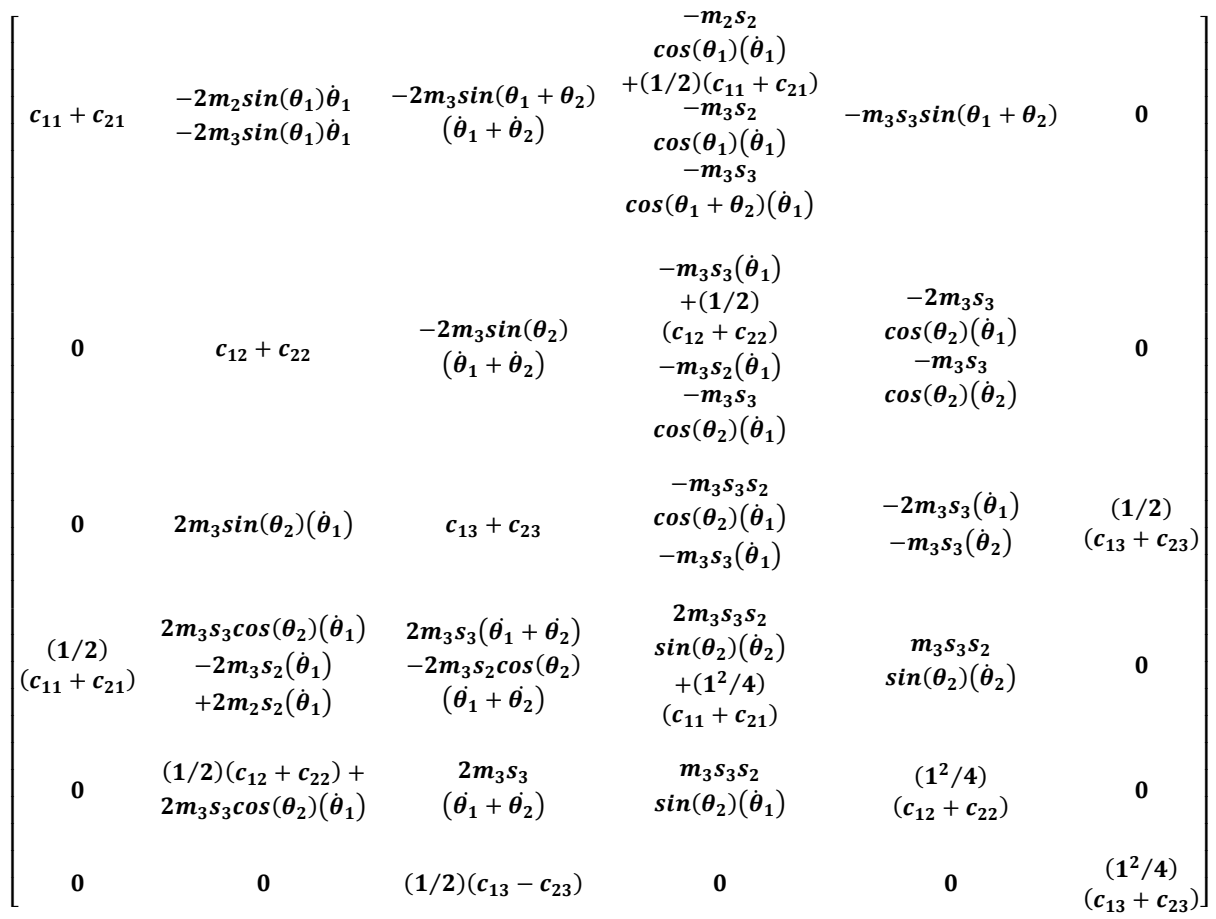

$$
G(\underline{q})=\left[\begin{array}{c}
-m_{1} g-m_{2} g+k_{11}\left(s_{1}+(1 / 2) \theta_{1}-s_{01}\right)+k_{21}\left(s_{1}-(1 / 2) \theta_{1}-s_{01}\right)-m_{3} g \\
-m_{2} g \cos \left(\theta_{1}\right)+k_{12}\left(s_{2}+(1 / 2) \theta_{2}-s_{02}\right)+k_{22}\left(s_{2}-(1 / 2) \theta_{2}-s_{02}\right)-m_{3} g \cos \left(\theta_{1}\right) \\
-m_{3} g \cos \left(\theta_{1}+\theta_{2}\right)+k_{13}\left(s_{3}+(1 / 2) \theta_{3}-s_{03}\right)+k_{23}\left(s_{3}-(1 / 2) \theta_{3}-s_{03}\right) \\
m_{2} s_{2} g \sin \left(\theta_{1}\right)+m_{3} s_{3} g \sin \left(\theta_{1}+\theta_{2}\right)+m_{3} s_{2} g \sin \left(\theta_{1}\right)+k_{11}\left(s_{1}+(1 / 2) \theta_{1}-s_{01}\right)(1 / 2) \\
+k_{21}\left(s_{1}-(1 / 2) \theta_{1}-s_{01}\right)(-1 / 2) \\
m_{3} s_{3} g \sin \left(\theta_{1}+\theta_{2}\right)+k_{12}\left(s_{2}+(1 / 2) \theta_{2}-s_{02}\right)(1 / 2)+k_{22}\left(s_{2}-(1 / 2) \theta_{2}-s_{02}\right)(-1 / 2) \\
k_{13}\left(s_{3}+(1 / 2) \theta_{3}-s_{03}\right)(1 / 2)+k_{23}\left(s_{3}-(1 / 2) \theta_{3}-s_{03}\right)(-1 / 2)
\end{array}\right]
$$

\subsection{Sliding Mode Controller}

Consider a nonlinear single input dynamic system is defined by [7-20]: 
vector, $\boldsymbol{f}(\boldsymbol{x})$ is unknown or uncertainty, and $\boldsymbol{b}(\boldsymbol{x})$ is of known sign function. The main goal to design this controller is train to the desired state; $\boldsymbol{x}_{\boldsymbol{d}}=$ $\left[x_{d}, \dot{x}_{d}, \ddot{x}_{d}, \ldots, x_{d}^{(n-1)}\right]^{T}$, and trucking error vector is defined by [7-20]:

$$
\widetilde{x}=x-x_{d}=\left[\widetilde{x}, \ldots, \widetilde{x}^{(n-1)}\right]^{T}
$$

A time-varying sliding surface $\boldsymbol{s}(\boldsymbol{x}, \boldsymbol{t})$ in the state space $\boldsymbol{R}^{\boldsymbol{n}}$ is given by [7-20]:

$$
s(x, t)=\left(\frac{d}{d t}+\lambda\right)^{n-1} \widetilde{x}=0
$$

where $\lambda$ is the positive constant. To further penalize tracking error, integral part can be used in sliding surface part as follows [7-20]:

$$
\boldsymbol{s}(\boldsymbol{x}, \boldsymbol{t})=\left(\frac{d}{d t}+\lambda\right)^{n-1}\left(\int_{0}^{t} \tilde{\boldsymbol{x}} \boldsymbol{d t}\right)=\mathbf{0}
$$

The main target in this methodology is kept the sliding surface slope $\boldsymbol{s}(\boldsymbol{x}, \boldsymbol{t})$ near to the zero. Therefore, one of the common strategies is to find input $\boldsymbol{U}$ outside of $\boldsymbol{s}(\boldsymbol{x}, \boldsymbol{t})$ [7-20].

$$
\frac{1}{2} \frac{d}{d t} s^{2}(x, t) \leq-\zeta|s(x, t)|
$$

where $\zeta$ is positive constant.

$$
\text { If } \mathbf{S}(\mathbf{0})>0 \rightarrow \frac{\mathrm{d}}{\mathrm{dt}} \mathbf{S}(\mathrm{t}) \leq-\zeta
$$

To eliminate the derivative term, it is used an integral term from $\mathrm{t}=0$ to $\mathrm{t}=\boldsymbol{t}_{\text {reach }}$

$$
\begin{gathered}
\int_{t=0}^{t=t_{\text {reach }}} \frac{d}{d t} S(t) \leq-\int_{t=0}^{t=t_{\text {reach }}} \eta \rightarrow \\
S\left(t_{\text {reach }}\right)-S(0) \leq-\zeta\left(t_{\text {reach }}-0\right)
\end{gathered}
$$

Where $t_{\text {reach }}$ is the time that trajectories reach to the sliding surface so, suppose $\mathrm{S}\left(t_{\text {reach }}=0\right)$ defined as;

$$
0-S(0) \leq-\eta\left(t_{\text {reach }}\right) \rightarrow t_{\text {reach }} \leq \frac{S(0)}{\zeta}
$$

And

$$
\text { if } \begin{aligned}
S(0) & <0 \rightarrow 0-S(0) \leq-\boldsymbol{\eta}\left(\boldsymbol{t}_{\text {reach }}\right) \rightarrow \\
\boldsymbol{S}(\mathbf{0}) & \leq-\zeta\left(\boldsymbol{t}_{\text {reach }}\right) \rightarrow \boldsymbol{t}_{\text {reach }} \leq \frac{|\boldsymbol{S}(\mathbf{0})|}{\eta}
\end{aligned}
$$

Equation (14) guarantees time to reach the sliding surface is smaller than $\frac{|\boldsymbol{S}(\mathbf{0})|}{\zeta}$ since the trajectories are outside of $S(t)$.

$$
\text { if } S_{t_{\text {reach }}}=S(0) \rightarrow \operatorname{error}\left(x-x_{d}\right)=0
$$

suppose $\mathrm{S}$ is defined as

$$
s(x, t)=\left(\frac{d}{d t}+\lambda\right) \quad \widetilde{x}=\left(\dot{\mathbf{x}}-\dot{\mathbf{x}}_{\mathrm{d}}\right)+
$$

The derivation of $S$, namely, $\dot{S}$ can be calculated as the following;

$$
\dot{S}=\left(\ddot{\mathbf{x}}-\ddot{\mathbf{x}}_{\mathbf{d}}\right)+\lambda\left(\dot{\mathbf{x}}-\dot{\mathbf{x}}_{\mathbf{d}}\right)
$$

suppose the second order system is defined as;

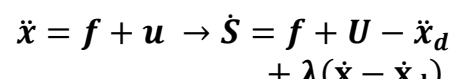

Where $\boldsymbol{f}$ is the dynamic uncertain, and also since $S=$ 0 and $\dot{S}=0$, to have the best approximation, $\widehat{\boldsymbol{U}}$ is defined as

$$
\widehat{U}=-\widehat{f}+\ddot{x}_{d}-\lambda\left(\dot{\mathbf{x}}-\dot{\mathbf{x}}_{\mathbf{d}}\right)
$$

A simple solution to get the sliding condition when the dynamic parameters have uncertainty is the switching control law [52-53]:

$$
U_{d i s}=\widehat{U}-K(\vec{x}, t) \cdot \operatorname{sgn}(s)
$$

where the switching function $\mathbf{s g n}(\mathbf{S})$ is defined as [8$18]$

$$
\operatorname{sgn}(s)= \begin{cases}1 & s>0 \\ -1 & s<0 \\ 0 & s=0\end{cases}
$$

and the $\boldsymbol{K}(\overrightarrow{\boldsymbol{x}}, \boldsymbol{t})$ is the positive constant. Suppose by (22) the following equation can be written as,

$$
\begin{aligned}
\frac{1}{2} \frac{d}{d t} s^{2}(x, t)=\dot{S} & \cdot S \\
= & {[f-\widehat{f}-K \operatorname{sgn}(s)] } \\
& \cdot S \\
& =(f-\widehat{f}) \cdot S-K|S|
\end{aligned}
$$

and if the equation (20) instead of (21) the sliding surface can be calculated as

$$
\begin{aligned}
& s(x, t)=\left(\frac{d}{d t}+\lambda\right)^{2}\left(\int_{0}^{t} \widetilde{x} d t\right)= \\
& \left(\dot{x}-\dot{x}_{d}\right)+2 \lambda\left(\dot{x}-\dot{x}_{d}\right)-\lambda^{2}\left(x-x_{d}\right)
\end{aligned}
$$

in this method the approximation of $\boldsymbol{U}$ is computed as [7-20]

$$
\begin{aligned}
\widehat{U}=-\widehat{f}+\ddot{x}_{d}-2 & \lambda\left(\dot{\mathbf{x}}-\dot{\mathbf{x}}_{\mathbf{d}}\right) \\
& +\lambda^{2}\left(\mathbf{x}-\mathbf{x}_{\mathbf{d}}\right)
\end{aligned}
$$

Based on above discussion, the sliding mode control law for a multi degrees of freedom robot manipulator is written as $[1,6]$ : 


$$
\tau=\tau_{e q}+\tau_{\text {dis }}
$$

Where, the model-based component $\boldsymbol{\tau}_{\boldsymbol{e q}}$ is the nominal dynamics of systems calculated as follows [1]:

$$
\tau_{e q}=\left[M^{-1}(B+C+G)+\dot{S}\right] M
$$

and $\boldsymbol{\tau}_{\text {dis }}$ is computed as [1];

$$
\tau_{d i s}=K \cdot \operatorname{sgn}(S)
$$

By (26) and (27) the sliding mode control of robot manipulator is calculated as;

$$
\begin{gathered}
\tau=\left[M^{-1}(B+C+G)+\dot{S}\right] M+K \\
\cdot \operatorname{sgn}(S)
\end{gathered}
$$

where $S=\lambda e+\dot{e}$ in PD-SMC and $S=\lambda e+\dot{e}+$ $\left(\frac{\lambda}{2}\right)^{2} \sum e$ in PID-SMC.

\subsubsection{Proof of Stability}

The lyapunov formulation can be written as follows,

$$
V=\frac{1}{2} S^{T} . D \cdot S
$$

The derivation of $V$ can be determined as,

$$
\dot{V}=\frac{1}{2} S^{T} \cdot \dot{D} \cdot S+S^{T} D \dot{S}
$$

The dynamic equation of robot manipulator can be written based on the sliding surface as

$$
D \dot{S}=-V S+D \dot{S}+f+C+G
$$

It is assumed that

$$
S^{T}(\dot{D}-2 f+C+G) S=0
$$

By substituting (43) in (44)

$$
\begin{aligned}
& \dot{V}=\frac{1}{2} S^{T} \dot{D} S-S^{T} f+C S+S^{T}(D \dot{S}+f+ \\
& C S+G)=S^{T}(D \dot{S}+f+C S+G)
\end{aligned}
$$

Suppose the control input is written as follows

$$
\begin{aligned}
& \widehat{U}=U_{\text {Nonlınear }}+\widehat{U_{d i s}}=\left[\widehat{D^{-1}}(f+C+\right. \\
& G)+\dot{S}] \widehat{D}+K \cdot \operatorname{sgn}(S)+f+C S+G
\end{aligned}
$$

by replacing the equation (34) in (30)

$$
\begin{aligned}
& \dot{V}=S^{T}(D \dot{S}+f+C+G-\widehat{D} \dot{S}- \\
& \widehat{f+C} S+G-K \operatorname{sgn}(S)=S^{T}(\widetilde{D} \dot{S}+ \\
& \widetilde{f+C} S+G-K \operatorname{sgn}(S)) \\
& |\widetilde{D} \dot{S}+\widetilde{f+C S}+G| \\
& \leq|\widetilde{D} \dot{S}|+|\widetilde{f+C} S+G|
\end{aligned}
$$
and

The Lemma equation in robot arm system can be written as follows

$$
\begin{gathered}
K_{u}=[|\widetilde{D} \dot{S}|+|f+C S+G|+\eta]_{i}, i \\
=1,2,3,4, \ldots
\end{gathered}
$$

And finally;

$$
\dot{V} \leq-\sum_{i=1}^{n} \eta_{i}\left|S_{i}\right|
$$

\subsubsection{Fuzzy Logic Methodology}

Based on foundation of fuzzy logic methodology; fuzzy logic controller has played important rule to design nonlinear controller for nonlinear and uncertain systems [53]. However the application area for fuzzy control is really wide, the basic form for all command types of controllers consists of;

Input fuzzification (binary-to-fuzzy $[\mathrm{B} / \mathrm{F}]$ conversion)

Fuzzy rule base (knowledge base), Inference engine and Output defuzzification (fuzzy-to-binary [F/B] conversion). Figure 1 shows the fuzzy controller part.

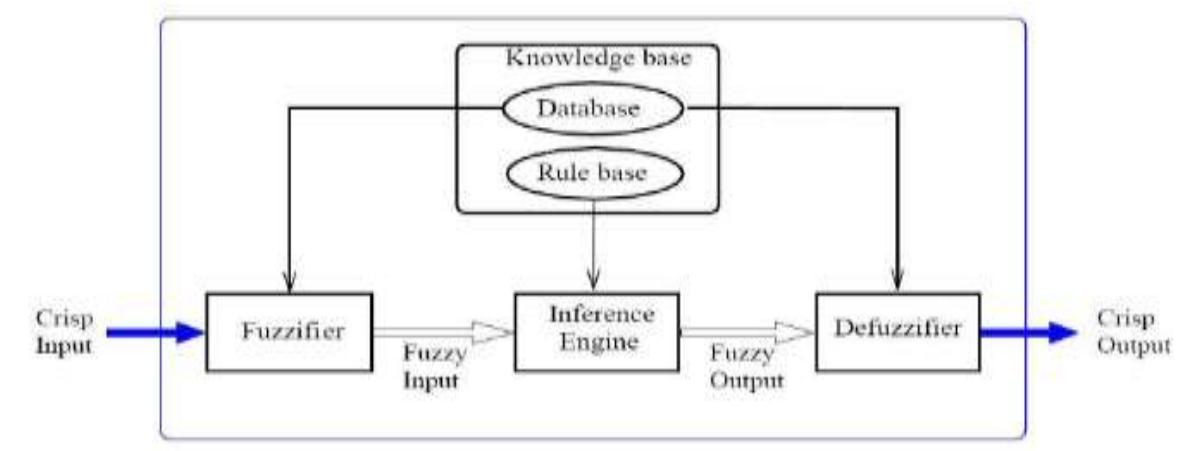

Fig. 1: Fuzzy Controller Part 
The fuzzy inference engine offers a mechanism for transferring the rule base in fuzzy set which it is divided into two most important methods, namely, Mamdani method and Sugeno method. Mamdani method is one of the common fuzzy inference systems and he designed one of the first fuzzy controllers to control of system engine. Mamdani's fuzzy inference system is divided into four major steps: fuzzification, rule evaluation, aggregation of the rule outputs and defuzzification. Michio Sugeno use a singleton as a membership function of the rule consequent part. The following definition shows the Mamdani and Sugeno fuzzy rule base [22-33]

\section{if $x$ is $A$ and $y$ is $B$ then $z$ is $C$ 'mamdani' if $x$ is $A$ and $y$ is B then $z$ is $f(x, y)$ 'sugeno'}

When $x$ and $y$ have crisp values fuzzification calculates the membership degrees for antecedent part. Rule evaluation focuses on fuzzy operation $(A N D / O R)$ in the antecedent of the fuzzy rules. The aggregation is used to calculate the output fuzzy set and several methodologies can be used in fuzzy logic controller aggregation, namely, Max-Min aggregation, Sum-Min aggregation, Max-bounded product, Max-drastic product, Max-bounded sum, Max-algebraic sum and Min-max. Defuzzification is the last step in the fuzzy inference system which it is used to transform fuzzy set to crisp set. Consequently defuzzification's input is the aggregate output and the defuzzification's output is a crisp number. Centre of gravity method (COG) and Centre of area method (COA) are two most common defuzzification methods.

\section{Methodology}

Conversely pure sliding mode controller is a highquality nonlinear controller; it has two important problems; chattering phenomenon and nonlinear equivalent dynamic formulation in uncertain dynamic parameter. To reduce the chattering phenomenon and equivalent dynamic problems, this research is focused on applied parallel fuzzy logic theorem in sliding mode controller as a compensator. Fuzzy logic theory is used in parallel with sliding mode controller to compensate the limited uncertainty in system's dynamic. In this method fuzzy logic theorem is applied to sliding mode controller to remove the nonlinear uncertainty part which it is based on nonlinear dynamic formulation. To achieve this goal, the dynamic equivalent part of pure sliding mode controller is modeled by Mamdani's performance/ error-based fuzzy logic methodology. Another researcher's method is based on applied fuzzy logic theorem in sliding mode controller to design a fuzzy model-based controller. This technique was employed to obtain the desired control behavior with a number of information about dynamic model of system and a fuzzy switching control was applied to reinforce system performance. Reduce or eliminate the chattering phenomenon and reduce the error are played important role, therefore switching method is used beside the artificial intelligence part to solve the chattering problem with respect to reduce the error. Equivalent part of sliding mode controller is based on nonlinear dynamic formulations of robot manipulator. Robot manipulator's dynamic formulations are highly nonlinear and some of parameters are unknown therefore design a controller based on dynamic formulation is complicated. To solve this challenge parallel fuzzy logic methodology is applied to sliding mode controller. In this method fuzzy logic method is used to compensate some dynamic formulation that they are used in equivalent part. To solve the challenge of sliding mode controller based on nonlinear dynamic formulation this research is focused on compensate the nonlinear equivalent formulation by parallel fuzzy logic controller. In this method; dynamic nonlinear equivalent part is modelled by performance/error-based fuzzy logic controller. In this method; error based Mamdani's fuzzy inference system has considered with two inputs, one output and totally 49 rules. For both sliding mode controller and parallel fuzzy inference system plus sliding mode controller applications the system performance is sensitive to the sliding surface slope coefficient $(\lambda)$. For instance, if large value of $\lambda$ is chosen the response is very fast the system is unstable and conversely, if small value of $\boldsymbol{\lambda}$ is considered the response of system is very slow but system is stable. Therefore to have a good response, compute the best value sliding surface slope coefficient is very important. In parallel fuzzy inference system compensator of sliding mode controller the PD-sliding surface is defined as follows:

$$
S=\dot{e}+\lambda_{1} e
$$

where $\lambda_{1}=\operatorname{diag}\left[\lambda_{11}, \lambda_{12}, \lambda_{13}\right]$. The time derivative of $\mathrm{S}$ is computed;

$$
\dot{S}=\ddot{q}_{d}+\lambda_{1} \dot{e}
$$

Based on Figure 3, the parallel fuzzy error-based compensator of sliding mode controller's output is written;

$$
\hat{\boldsymbol{\tau}}=\boldsymbol{\tau}_{e q_{f u z z y}}+\boldsymbol{\tau}_{S M C}
$$

Based on fuzzy logic methodology

$$
f(x)=U_{f u z z y}=\sum_{l=1}^{M} \theta^{T} \zeta(x)
$$

where $\boldsymbol{\theta}^{\boldsymbol{T}}$ is adjustable parameter (gain updating factor) and $\boldsymbol{\zeta}(\boldsymbol{x})$ is defined by;

$$
\zeta(\boldsymbol{x})=\frac{\sum_{i} \mu\left(x_{i}\right) x_{i}}{\sum_{i} \mu\left(x_{i}\right)}
$$


and $\boldsymbol{\tau}_{M P I D}$ is computed as;

$$
\begin{aligned}
& \tau_{M P+I+D}=K_{p_{a}} e+K_{V_{a}}\left(\frac{s}{0.1 S+1}\right) e(t)+ \\
& K_{I} \sum e
\end{aligned}
$$

Design an error-based parallel fuzzy compensate of equivalent part based on Mamdani's fuzzy inference method has four steps, namely, fuzzification, fuzzy rule base and rule evaluation, aggregation of the rule output (fuzzy inference system) and defuzzification.

Fuzzification: the first step in fuzzification is determine inputs and outputs which, it has one input $\left(\tau_{M P I D}\right)$ and one output $\left(\tau_{\text {fuzzy }}\right)$. The second step is chosen an appropriate membership function for input and output which, to simplicity in implementation triangular membership function is selected in this research. The third step is chose the correct labels for each fuzzy set which, in this research namely as linguistic variable. Based on experience knowledge the linguistic variables for input $\tau_{M P I D}$ are; Negative Big (NB), Negative Medium (NM), Negative Small (NS), Zero (Z), Positive Small (PS), Positive Medium (PM), Positive Big (PB), and based on experience knowledge it is quantized into thirteen levels represented by: $-1,-0.83,-0.66,-0.5$, $0.33,-0.16,0,0.16,0.33,0.5,0.66,0.83,1$ and the linguistic variables to find the output are; Large Left (LL), Medium Left (ML), Small Left (SL), Zero (Z), Small Right (SR), Medium Right (MR), Large Right (LR) and it is quantized in to thirteen levels represented by: $-85,-70.8,-56.7,-42.5,-28.3,-14.2,0,14.2,28.3$, $42.5,56.7,70.8,85$.

Fuzzy rule base and rule evaluation: the first step in rule base and evaluation is to provide a least structured method to derive the fuzzy rule base which, expert experience and control engineering knowledge is used because this method is the least structure of the other one and the researcher derivation the fuzzy rule base from the knowledge of system operate and/or the classical controller. Design the rule base of fuzzy inference system can play important role to design the best performance of parallel fuzzy plus sliding mode controller, that to calculate the fuzzy rule base the researcher is used to heuristic method which, it is based on the behavior of the control of robot manipulator. The complete rule base for this controller is shown in Table 1. Rule evaluation focuses on operation in the antecedent of the fuzzy rules in fuzzy sliding mode controller. This part is used $A N D / O R$ fuzzy operation in antecedent part which $A N D$ operation is used.

Table 1: Design Rule Base of Fuzzy Inference System

\begin{tabular}{||l|l|l|l|l|l|l|l||}
\hline $\boldsymbol{\tau}_{\text {MPID }}$ & $\mathrm{NB}$ & $\mathrm{NM}$ & $\mathrm{NS}$ & $\mathrm{Z}$ & $\mathrm{PS}$ & $\mathrm{PM}$ & $\mathrm{PB}$ \\
\hline $\boldsymbol{\tau}_{\text {Fuzzy }}$ & $\mathrm{LL}$ & $\mathrm{ML}$ & $\mathrm{SL}$ & $\mathrm{Z}$ & $\mathrm{SR}$ & $\mathrm{MR}$ & $\mathrm{LR}$ \\
\hline
\end{tabular}

Aggregation of the rule output (Fuzzy inference): based onfuzzy methodology, Max-Min aggregation is used in this work.

Defuzzification: The last step to design fuzzy inference in our parallel fuzzy compensator plus sliding mode controller is defuzzification. This part is used to transform fuzzy set to crisp set, therefore the input for defuzzification is the aggregate output and the output of it is a crisp number. Based on fuzzy methodology Center of gravity method $(C O G)$ is used in this research.

For sliding mode controller application the system performance is sensitive to the sliding surface slope coefficient $(\boldsymbol{\lambda})$. For instance, if large value of $\boldsymbol{\lambda}$ is chosen the response is very fast the system is unstable and conversely, if small value of $\boldsymbol{\lambda}$ is considered the response of system is very slow but system is stable. Therefore to have a good response, compute the best value sliding surface slope coefficient is very important.

Gradient descent algorithm is based on improving the input parameters by moving iteratively in the direction of the estimated gradient of the response of interest. One of the major concerns with this type of algorithm is the estimation of the gradient and its statistical properties. Naturally, the heart of gradient \{based algorithms is the technique used to estimate the gradient. Here we present the most common methods used in the simulation optimization literature. For further details the reader is referred to [12]. Gradient descent is based on the observation that if the multivariable function $F(x)$ is defined and differentiable in a neighborhood of a point $a$, then $F(x)$ decreases fastest if one goes from $a$ in the direction of the negative gradient of $F$ at,$a-\nabla F(a)$. It follows that, if

$$
b=a-\gamma \nabla F(a)
$$

for $\gamma \rightarrow 0$ a small enough number, then $F(a)<F(b)$. With this observation in mind, one starts with a guess $x_{0}$ for a local minimum of $F$, and considers the sequence $x_{0}, x_{1}, x_{2}, \ldots .$. such that

$$
\boldsymbol{X}_{\boldsymbol{n}+\mathbf{1}}=\boldsymbol{X}_{\boldsymbol{n}}-\gamma_{n} \nabla F\left(X_{n}\right), \quad n \geq 0
$$

We have

$$
F\left(X_{0}\right) \geq F\left(X_{1}\right) \geq F\left(X_{2}\right), \geq \cdots
$$

So hopefully the sequence $\left(X_{n}\right)$ converges to the desired local minimum. Note that the value of the step size $\gamma$ is allowed to change at every iteration. With certain assumptions on the function $F$ (for example, $F$ convex and $\nabla F$ Lipschitz) and particular choices of $\gamma($ e.g., chosen via a line search that satisfies the Wolfe conditions), convergence to a local minimum can be guaranteed. When the function $F$ is convex, all local minima are also global minima, so in this case gradient descent can converge to the global solution. 


\section{Results and Discussion}

Evolutionary optimal algorithm fuzzy sliding mode controller (GDFSMC) was tested to Step response trajectory. In this simulation, to control position of continuum robot the first, second, and third joints are moved from home to final position without and with external disturbance. The simulation was implemented in MATLAB/SIMULINK environment. These systems are tested by band limited white noise with a predefined $40 \%$ of relative to the input signal amplitude. This type of noise is used to external disturbance in continuous and hybrid systems and applied to nonlinear dynamic of these controllers.

\section{GDA Fuzzy Sliding Mode Controller Optimization:}

In GDA fuzzy sliding mode controller; controllers performance are depended on the gain updating factor $(K)$ and sliding surface slope coefficient $(\lambda)$. These two coefficients are computed by GDA optimization; Figures 2 and 3.

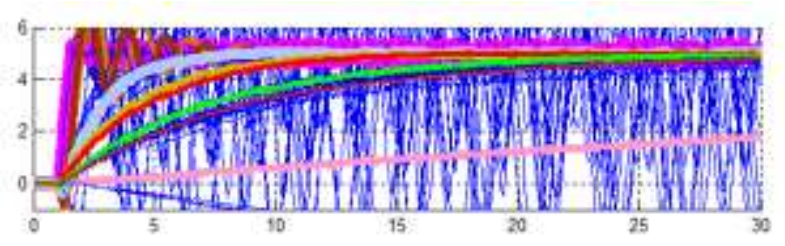

Fig. 2: Trajectory Gradient descent optimization in sliding mode controller

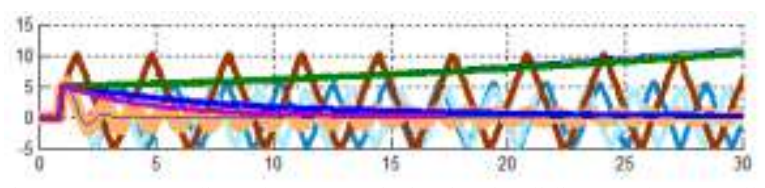

Fig. 3: Error; Gradient descent optimization in sliding mode controller

Tracking performances: In GDA fuzzy sliding mode controller; the performance is depended on the gain updating factor $(K)$ and sliding surface slope coefficient $(\lambda)$. These two coefficients are computed by gradient descent optimization. Figure 4 shows tracking performance in GDASMC and SMC without disturbance for step trajectory.
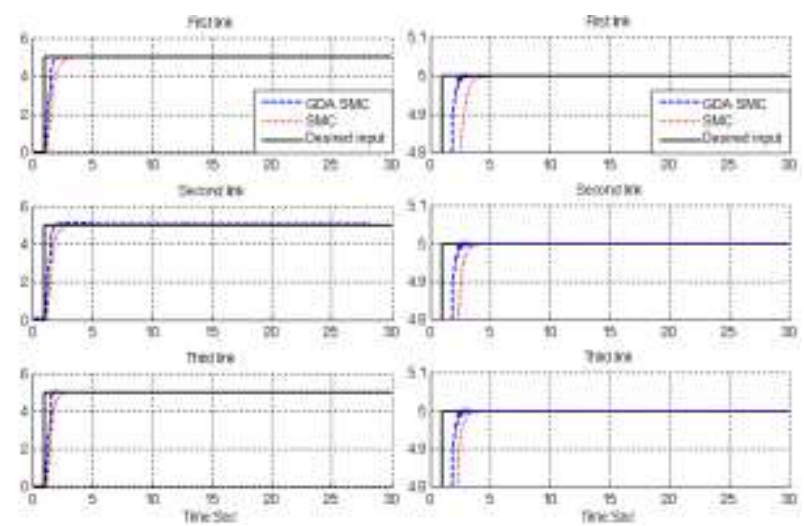

Fig. 4: Gradient descent optimal SMC vs. Trial and error SMC
Disturbance rejection: Figure 5 shows the power disturbance elimination in GDASMC and SMC with disturbance for step trajectory. The disturbance rejection is used to test the robustness comparisons of these controllers for step trajectory. A band limited white noise with predefined of $40 \%$ the power of input signal value is applied to the step trajectory. It found fairly fluctuations in trajectory responses. Based on Figure 5; by comparing step response trajectory with $40 \%$ disturbance of relative to the input signal amplitude in SMC and GDASMC, GDAFSMC's overshoot about $\mathbf{( 0 . 5 \% )}$ is lower than FTFSMC's (1.2\%).

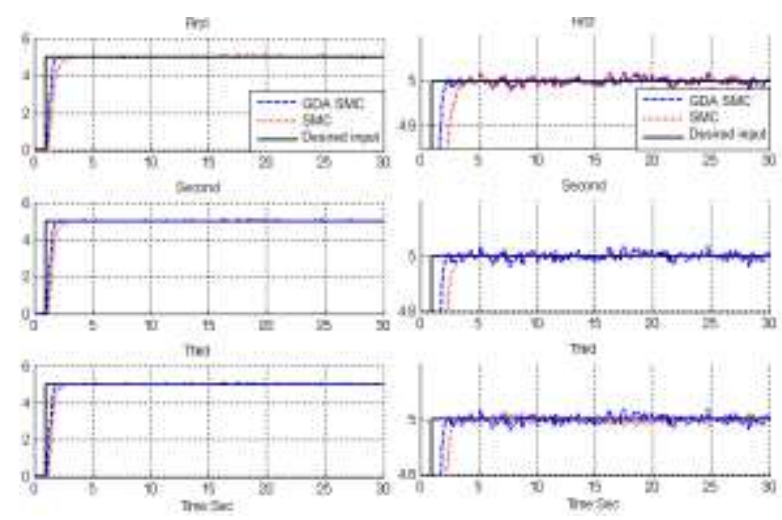

Fig. 5: Gradient descent optimal FSMC vs. SMC: in presence of $40 \%$ disturbance

Torque performance: Figure 6 and 7 have indicated the power of chattering rejection in GDASMC and SMC with $40 \%$ disturbance and without disturbance. Figure 5 shows torque performance for first three links continuum robot in GDASMC and SMC without disturbance. Based on Figure 7, GDASMC and SMC give considerable torque performance in certain system and both of controllers eliminate the chattering phenomenon in this situation.
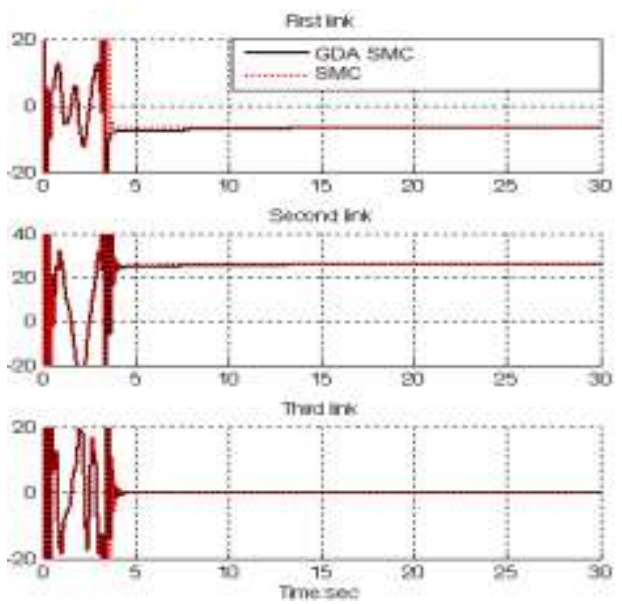

Fig. 6: Gradient descent optimal FSMC vs. SMC: Torque performance

Figure 7 has indicated the robustness in torque performance for first three links continuum robot in GDASMC and SMC in presence of $40 \%$ disturbance. 
Based on Figure 7, it is observed that both of two controllers have oscillation. This is mainly because pure SMC and optimal sliding mode controller are robust but they have limitation in presence of external disturbance.
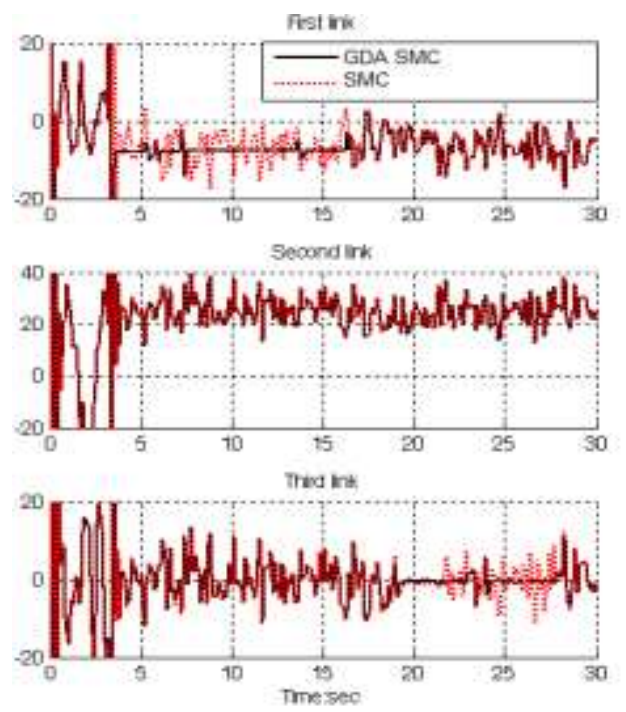

Fig. 7: Gradient descent optimal SMC vs. SMC: Torque performance with noise

The GDASMC gives significant steady state error performance when compared to SMC. When applied $40 \%$ disturbances in SMC the RMS error increased rapidly approximately $22 \%$ (percent of increase the SMC RMS error $\left.=\frac{(40 \% \text { disturbance } R M S \text { error }}{\text { no disturbanceRMS error }}=\frac{0.22 e-4}{1 e-7}=22 \%\right)$ and in GDASMC the RMS error increased approximately $9.17 \%$ (percent of increase the GDASMC RMS error $\left.=\frac{(40 \% \text { disturbance } \text { RMS error }}{\text { no disturbance } \text { RMS error }}=\frac{11 e-4}{1.2 e-6}=9.17 \%\right)$.

\section{Conclusion}

The central issues and challenges of non linear control and estimation problems are to satisfy the desired performance objectives in the presence of noises, disturbances, parameter perturbations, un-modeled dynamics, sensor failures, actuator failures, time delays, etc. Evaluation algorithm fuzzy sliding mode control has shown growing popularity in both industry and academia. To improve the optimality and robustness, we have proposed optimal gradient descent control for nonlinear systems with general performance criteria. Sliding mode method provides us an effective tool to control nonlinear systems through the switching function and dynamic formulation of nonlinear system. Mixed performance criteria have been used to design the controller and the relative weighting matrices of these criteria can be achieved by choosing different coefficient matrices. The optimal control can be obtained by solving gradient descent at each time. The simulation studies show that the proposed method provides a satisfactory alternative to the existing nonlinear control approaches.

\section{Acknowledgment}

The authors would like to thank the anonymous reviewers for their careful reading of this paper and for their helpful comments. This work was supported by the Institute of Advanced Science and Technology (IRANSSP) Research and Development Corporation Program of Iran under grant no. 2013-Persian Gulf-2B.

\section{References}

[1] T. R. Kurfess, Robotics and automation handbook: CRC, 2005.

[2] J. J. E. Slotine and W. Li, Applied nonlinear control vol. 461: Prentice hall Englewood Cliffs, NJ, 1991.

[3] L. Cheng, et al., "Multi-agent based adaptive consensus control for multiple manipulators with kinematic uncertainties," 2008, pp. 189-194.

[4] J. J. D'Azzo, et al., Linear control system analysis and design with MATLAB: CRC, 2003.

[5] B. Siciliano and O. Khatib, Springer handbook of robotics: Springer-Verlag New York Inc, 2008.

[6] I. Boiko, et al., "Analysis of chattering in systems with second-order sliding modes," IEEE Transactions on Automatic Control, vol. 52, pp. 2085-2102, 2007.

[7] J. Wang, et al., "Indirect adaptive fuzzy sliding mode control: Part I: fuzzy switching," Fuzzy Sets and Systems, vol. 122, pp. 21-30, 2001.

[8] F. Piltan, et al., "Artificial Control of Nonlinear Second Order Systems Based on AFGSMC," Australian Journal of Basic and Applied Sciences, 5(6), pp. 509-522, 2011.

[9] V. Utkin, "Variable structure systems with sliding modes," Automatic Control, IEEE Transactions on, vol. 22, pp. 212-222, 2002.

[10] R. A. DeCarlo, et al., "Variable structure control of nonlinear multivariable systems: a tutorial," Proceedings of the IEEE, vol. 76, pp. 212-232, 2002.

[11] K. D. Young, et al., "A control engineer's guide to sliding mode control," 2002, pp. 1-14.

[12] Samira Soltani \& Farzin Piltan, "Design Artificial Nonlinear Controller Based on Computed Torque like Controller with Tunable Gain", World Applied Science Journal (WASJ), 14 (9): 1306-1312, 2011.

[13] Farzin Piltan, Mohammadali Dialame, Abbas Zare \& Ali Badri,"Design Novel Lookup Table Changed Auto Tuning FSMC:Applied to Robot Manipulator", International Journal of Engineering, $6(1): 25-41,2012$ 
[14] Farzin Piltan, Mohammad Keshavarz, Ali Badri \& Arash Zargari,"Design Novel Nonlinear Controller Applied to RobotManipulator: Design New Feedback Linearization Fuzzy Controller with Minimum Rule Base Tuning Method", International Journal of Robotics and Automation,3 (1):1-12, 2012

[15] Farzin Piltan, Iman Nazari, Sobhan Siamak, Payman Ferdosali,"Methodology of FPGA-Based Mathematical error-Based Tuning Sliding Mode Controller", International Journal of Control and Automation, 5(1), 89-118, 2012

[16] Farzin Piltan, Bamdad Boroomand, Arman Jahed \& Hossein Rezaie, "Methodology of Mathematical Error-Based Tuning Sliding Mode Controller", International Journal of Engineering, 6 (2):96-117, 2012

[17] Farzin Piltan, Sara Emamzadeh, Zahra Hivand, Fatemeh Shahriyari \& Mina Mirazaei, "PUMA560 Robot Manipulator Position Sliding Mode Control Methods Using MATLAB/SIMULINK and Their Integration into Graduate/Undergraduate Nonlinear Control, Robotics and MATLAB Courses", International Journal of Robotics and Automation, 3(3):106-150, 2012

[18] Farzin Piltan, Ali Hosainpour, Ebrahim Mazlomian, Mohammad Shamsodini, Mohammad H. Yarmahmoudi, "Online Tuning Chattering Free Sliding Mode Fuzzy Control Design: Lyapunov Approach", International Journal of Robotics and Automation, 3(3):77-105, 2012

[19] Farzin Piltan, Mina Mirzaei, Forouzan Shahriari, Iman Nazari, Sara Emamzadeh, "Design Baseline Computed Torque Controller", International Journal of Engineering, 6(3): 129-141, 2012

[20] Farzin Piltan, Mohammad H. Yarmahmoudi, Mohammad Shamsodini, Ebrahim Mazlomian, Ali Hosainpour, 'PUMA-560 Robot Manipulator Position Computed Torque Control Methods Using MATLAB/SIMULINK and Their Integration into Graduate Nonlinear Control and MATLAB Courses", International Journal of Robotics and Automation, 3(3): 167-191, 2012

[21] Farzin Piltan, Hossein Rezaie, Bamdad Boroomand, Arman Jahed, "Design Robust Backstepping on-line Tuning Feedback Linearization Control Applied to IC Engine", International Journal of Advance Science and Technology, 11:40-22, 2012

[22] Farzin Piltan, Mohammad R. Rashidian, Mohammad Shamsodini and Sadeq Allahdadi, Effect of Rule Base on the Fuzzy-Based Tuning Fuzzy Sliding Mode Controller: Applied to $2^{\text {nd }}$ Order Nonlinear System", International Journal of Advanced Science and Technology, 46:39-70, 2012
[23] Farzin Piltan, Arman Jahed, Hossein Rezaie and Bamdad Boroomand, "Methodology of Robust Linear On-line High Speed Tuning for Stable Sliding Mode Controller: Applied to Nonlinear System", International Journal of Control and Automation, 5(3): 217-236, 2012

[24] Farzin Piltan, Bamdad Boroomand, Arman Jahed and Hossein Rezaie, "Performance-Based Adaptive Gradient Descent Optimal Coefficient Fuzzy Sliding Mode Methodology", International Journal of Intelligent Systems and Applications, , vol.4, no.11, pp.40-52, 2012.

[25] Farzin Piltan, Mehdi Akbari, Mojdeh Piran , Mansour Bazregar, ”Design Model Free Switching Gain Scheduling Baseline Controller with Application to Automotive Engine", International Journal of Information Technology and Computer Science, vol.5, no.1, pp.65-73, 2013.DOI: 10.5815/ijitcs.2013.01.07.

[26] Farzin Piltan, Mojdeh Piran , Mansour Bazregar, Mehdi Akbari, "Design High Impact Fuzzy Baseline Variable Structure Methodology to Artificial Adjust Fuel Ratio", International Journal of Intelligent Systems and Applications, vol.5, no.2, pp.59-70, 2013.DOI: 10.5815/ijisa.2013.02.0.

[27] Farzin Piltan, M. Bazregar, M. kamgari, M. Akbari and M. Piran, "Adjust the Fuel Ratio by High Impact Chattering Free Sliding Methodology with Application to Automotive Engine", International Journal of Hybrid Information Technology, 6(1), 2013.

[28] Farzin Piltan, S. Zare , F. ShahryarZadeh, M. Mansoorzadeh, M. kamgari, "Supervised Optimization of Fuel Ratio in IC Engine Based on Design Baseline Computed Fuel Methodology", International Journal of Information Technology and Computer Science, vol.5, no.4, pp.76-84, 2013.DOI: 10.5815/ijitcs.2013.04.09.

[29] Farzin Piltan, M. Mansoorzadeh, S. Zare, F.Shahryarzadeh, M. Akbari, "Artificial Tune of Fuel Ratio: Design a Novel SISO Fuzzy Backstepping Adaptive Variable Structure Control", International Journal of Electrical and Computer Engineering, 3(2), 2013.

[30] M. Bazregar, Farzin Piltan, A. Nabaee and M.M. Ebrahimi, "Parallel Soft Computing Control Optimization Algorithm for Uncertainty Dynamic Systems", International Journal of Advanced Science and Technology, 51, 2013.

[31] Farzin Piltan, M.H. Yarmahmoudi, M. Mirzaei, S. Emamzadeh, Z. Hivand, "Design Novel Fuzzy Robust Feedback Linearization Control with Application to Robot Manipulator", International Journal of Intelligent Systems and Applications , vol.5, no.5, pp.1-10, 2013.DOI: 10.5815/ijisa.2013.05.01. 
[32] Sh. Tayebi Haghighi, S. Soltani, Farzin Piltan, M. kamgari, S. Zare, "Evaluation Performance of IC Engine: Linear Tunable Gain Computed Torque Controller Vs. Sliding Mode Controller", International Journal of Intelligent Systems and Applications, vol.5, no.6, pp.78-88, 2013.DOI: 10.5815/ijisa.2013.06.10.

[33] Amin Jalali, Farzin Piltan, M. Keshtgar, M. Jalali, "Colonial Competitive Optimization Sliding Mode Controller with Application to Robot Manipulator", International Journal of Intelligent Systems and Applications, vol.5, no.7, pp.50-56, 2013. DOI: 10.5815/ijisa.2013.07.07.

[34] Salehi, Farzin Piltan, M. Mousavi, A. Khajeh, M. R. Rashidian, "Intelligent Robust Feed-forward Fuzzy Feedback Linearization Estimation of PID Control with Application to Continuum Robot", International Journal of Information Engineering and Electronic Business, vol.5, no.1, pp.1-16, 2013 DOI: 10.5815/ijieeb.2013.01.01.

[35] Farzin Piltan, M.J. Rafaati, F. Khazaeni, A. Hosainpour, S. Soltani, "A Design High Impact Lyapunov Fuzzy PD-Plus-Gravity Controller with Application to Rigid Manipulator", International Journal of Information Engineering and Electronic Business, vol.5, no.1, pp.17-25, 2013. DOI: 10.5815/ijieeb.2013.01.02.

[36] Amin Jalali, Farzin Piltan, A. Gavahian, M. Jalali, M. Adibi, "Model-Free Adaptive Fuzzy Sliding Mode Controller Optimized by Particle Swarm for Robot manipulator", International Journal of Information Engineering and Electronic Business, vol.5, no.1, pp.68-78, 2013. DOI: 10.5815/ijieeb.2013.01.08.

[37] Farzin Piltan, F. ShahryarZadeh ,M. Mansoorzadeh ,M. kamgari, S. Zare, "Robust Fuzzy PD Method with Parallel Computed Fuel Ratio Estimation Applied to Automotive Engine“", International Journal of Intelligent Systems and Applications, vol.5, no.8, pp.83-92, 2013. DOI: 10.5815/ijisa.2013.08.10.

[38] Farzin Piltan, A. Nabaee, M.M. Ebrahimi, M. Bazregar, "Design Robust Fuzzy Sliding Mode Control Technique for Robot Manipulator Systems with Modeling Uncertainties", International Journal of Information Technology and Computer Science, vol.5, no.8, pp.123-135, 2013. DOI: 10.5815/ijitcs.2013.08.12.

[39] Farzin Piltan, M. Mansoorzadeh, M. Akbari, S. Zare, F. ShahryarZadeh "Management of Environmental Pollution by Intelligent Control of Fuel in an Internal Combustion Engine" Global Journal of Biodiversity Science And Management, 3(1), 2013.

[40] M. M. Ebrahimit Farzin Piltan, M. Bazregar and A.R. Nabaee, "Intelligent Robust Fuzzy-Parallel
Optimization Control of a Continuum Robot Manipulator", International Journal of Control and Automation, 6(3), 2013.

[41] O.R. Sadrnia, Farzin Piltan, M. Jafari, M. Eram and M. Shamsodini, "Design PID Estimator Fuzzy plus Backstepping to Control of Uncertain Continuum Robot", International Journal of Hybrid Information Technology, 6(4), 2013.

[42] AminJalali, Farzin Piltan, H. Hashemzadeh, A. Hasiri, M.R Hashemzadeh, "Design Novel Soft Computing Backstepping Controller with Application to Nonlinear Dynamic Uncertain System", International Journal of Intelligent Systems and Applications, vol.5, no.10, pp.93-105, 2013. DOI: $10.5815 /$ ijisa.2013.10.12.

[43] M. Moosavi, M. Eram, A. Khajeh, O. Mahmoudi and Farzin Piltan, "Design New Artificial Intelligence Base Modified PID Hybrid Controller for Highly Nonlinear System", International Journal of Advanced Science and Technology, 57, 2013.

[44] S. Zahmatkesh, Farzin Piltan, K. Heidari, M. Shamsodini, S. Heidari, "Artificial Error Tuning Based on Design a Novel SISO Fuzzy Backstepping Adaptive Variable Structure Control" International Journal of Intelligent Systems and Applications, vol.5, no.11, pp.34-46, 2013. DOI: 10.5815/ijisa.2013.11.04.

[45] S. Heidari, Farzin Piltan, M. Shamsodini, K. Heidari and S. Zahmatkesh, "Design New Nonlinear Controller with Parallel Fuzzy Inference System Compensator to Control of Continuum Robot Manipulator", International Journal of Control and Automation, 6(4), 2013.

[46] FarzinPiltan, M. Kamgari, S. Zare, F. ShahryarZadeh, M. Mansoorzadeh, "Design Novel Model Reference Artificial Intelligence Based Methodology to Optimized Fuel Ratio in IC Engine", International Journal of Information Engineering and Electronic Business, vol.5, no.2, pp.44-51, 2013. DOI: 10.5815/ijieeb.2013.02.07.

[47] Farzin Piltan, Mehdi Eram, Mohammad Taghavi, Omid Reza Sadrnia, Mahdi Jafari,"Nonlinear Fuzzy Model-base Technique to Compensate Highly Nonlinear Continuum Robot Manipulator", IJISA, vol.5, no.12, pp.135-148, 2013. DOI: 10.5815/ijisa.2013.12.12

[48] Amin Jalali, Farzin Piltan, Mohammadreza Hashemzadeh, Fatemeh BibakVaravi, Hossein Hashemzadeh,"Design Parallel Linear PD Compensation by Fuzzy Sliding Compensator for Continuum Robot", IJITCS, vol.5, no.12, pp.97112, 2013. DOI: 10.5815/ijitcs.2013.12.12

[49] Farzin Piltan, A. Hosainpour, S. Emamzadeh, I. Nazari, M. Mirzaie, "Design Sliding Mode Controller of with Parallel Fuzzy Inference System 
Compensator to Control of Robot Manipulator", International Journal of Robotics and Automation, Vol. 2, No. 4, December 2013, pp. 149 162.

[50] Farzin Piltan, Mahdi Jafari, Mehdi Eram, Omid Mahmoudi, Omid Reza Sadrnia, "Design Artificial Intelligence-Based Switching PD plus Gravity for Highly Nonlinear Second Order System", International Journal of Engineering and Manufacturing, vol.3, no.1, pp.38-57, 2013.DOI: 10.5815/ijem.2013.01.04

[51] Farzin Piltan, Sara Emamzadeh, Sara Heidari, Samaneh Zahmatkesh, Kamran Heidari, "Design Artificial Intelligent Parallel Feedback Linearization of PID Control with Application to Continuum Robot", International Journal of Engineering and Manufacturing, vol.3, no.2, pp.51-72, 2013.DOI: 10.5815/ijem.2013.02.04

[52] Mohammad Mahdi Ebrahimi, Farzin Piltan, Mansour Bazregar, AliReza Nabaee,"Artificial Chattering Free on-line Modified Sliding Mode Algorithm: Applied in Continuum Robot Manipulator", International Journal of Information Engineering and Electronic Business, vol.5, no.5, pp.57-69, 2013. DOI: 10.5815/ijieeb.2013.05.08

[53] Arman Jahed, Farzin Piltan, Hossein Rezaie, Bamdad Boroomand, "Design Computed Torque Controller with Parallel Fuzzy Inference System Compensator to Control of Robot Manipulator", International Journal of Information Engineering and Electronic Business, vol.5, no.3, pp.66-77, 2013. DOI: 10.5815/ijieeb.2013.03.08

[54] Mohammad Shamsodini, Farzin Piltan, Mahdi Jafari, Omid reza Sadrnia, Omid Mahmoudi,"Design Modified Fuzzy Hybrid Technique: Tuning By GDO", IJMECS, vol.5, no.8, pp.58-72, 2013.DOI: 10.5815/ijmecs.2013.08.07

[55] Mahdi Mirshekaran, Farzin Piltan, Zahra Esmaeili, Tannaz Khajeaian, Meysam Kazeminasab, "Design Sliding Mode Modified Fuzzy Linear Controller with Application to Flexible Robot Manipulator", IJMECS, vol.5, no.10, pp.53-63, 2013.DOI: 10.5815/ijmecs.2013.10.07.

\section{Authors' Profiles}

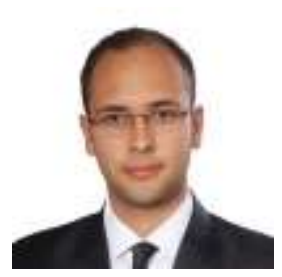

Ali Shahcheraghi is currently working as a primary researcher in the laboratory of Control and Robotic, Institute of Advance Science and Technology, IRAN SSP research and development Center. His current research interests are in the area of nonlinear control, artificial control system and robotics.

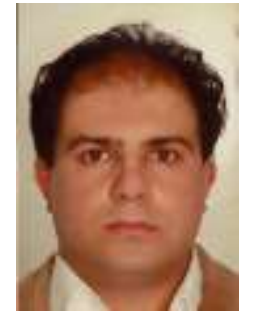

Farzin Piltan was born on 1975, Shiraz, Iran. In 2004 he is jointed Institute of Advance Science and Technology, Research and Development Center, IRAN SSP. Now he is a dean of Intelligent Control and Robotics Lab. In addition to 7 textbooks, Farzin Piltan is the main author of more than 100 scientific papers in refereed journals. He is editorial review board member for 'international journal of control and automation (IJCA), Australia, ISSN: 2005-4297; 'International Journal of Intelligent System and Applications (IJISA)', Hong Kong, ISSN:2074-9058; 'IAES international journal of robotics and automation, Malaysia, ISSN:2089-4856; 'International Journal of Reconfigurable and Embedded Systems', Malaysia, ISSN:2089-4864. His current research interests are nonlinear control, artificial control system and applied to FPGA, robotics and artificial nonlinear control and IC engine modeling and control.

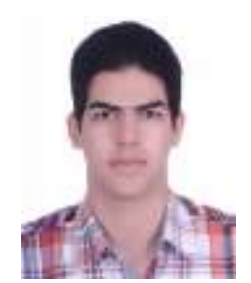

Masoud Mokhtar is currently working as a primary researcher in the laboratory of Control and Robotic Institute of Advance Science and Technology, IRAN SSP research and development Center. His current research interests are in the area of nonlinear control, artificial control system and robotics.

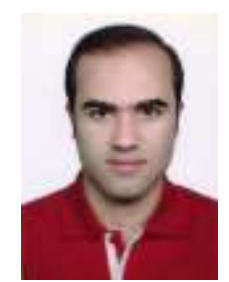

Omid Avatefipour is currently working as a primary researcher in the laboratory of Control and Robotic, Institute of Advance Science and Technology, IRAN SSP research and development Center. His current research interests are in the area of nonlinear control, artificial control system and robotics.

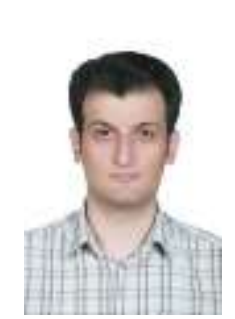

Alireza Khalilian is currently working as a primary researcher in the laboratory of Control and Robotic, Institute of Advance Science and Technology, IRAN SSP research and development Center. His current research interests are in the area of nonlinear control, artificial control system and robotics.

How to cite this paper: Ali Shahcheraghi, Farzin Piltan, Masoud Mokhtar, Omid Avatefipour, Alireza Khalilian,"Design a Novel SISO Off-line Tuning of Modified PID Fuzzy Sliding Mode Controller", IJITCS, vol.6, no.2, pp.72-83, 2014. DOI: $10.5815 /$ ijitcs.2014.02.10 